\title{
Allen's test in patients with peripheral artery disease
}

\section{Research Article}

Zoltán Ruzsa*1,2, Károly Tóth², Balázs Berta¹, István Koncz², György Szabó1, Zoltán Jambrik ${ }^{1}$, István Varga ${ }^{3}$, Kálmán Hüttl ${ }^{1}$, Béla Merkely¹, Attila Nemes ${ }^{4}$

1 Cardiovascular Center, Semmelweis University, Budapest, Hungary

2 Angiographic Laboratory, Bács-Kiskun County Hospital, Kecskemét, Hungary

3 Angiographic Laboratory, Kálmán Pándy County Hospital, Gyula, Hungary

4 2nd Department of Medicine and Cardiology Center, Medical Faculty, Albert Szent-Györgyi Clinical Center, University of Szeged, Szeged, Hungary

\section{Received 24 October 2012; Accepted 26 February 2013}

Abstract: Introduction. Transradial (TR) approach for coronary and peripheral angiography has become a popular technique. The Allen's test (AT) could be used to determine the presence of collateral flow in the hand. Recently, angiographic background of modified AT was evaluated, but patients with peripherial arterial disease (PAD) were excluded in these studies. Therefore, the present study was designed to assess reliability of AT in patients with symptomatic PAD. Methods. The present study comprised 92 symptomatic patients with PAD (Rutherford class 2-6). Perfusion of the hand was assessed with AT before outpatient peripheral angiography. Results. Significant RA stenosis $(n=6,12.5 \%)$ and UA stenosis $(n=26,54.2 \%)$ were found in 30 patients with positive AT $(62.5 \%)$. In patients with negative AT, only UA showed significant stenoses $(n=6,13.6 \%)$. Thirty-eight patients with positive AT had anatomic abnormality in the forearm arteries or in the palmar arch (79.2\%). Anatomic abnormality in the forearm arteries or in the palmar arch could be detected in 15 cases with negative AT $(34.1 \%, p<0.0001)$. Conclusions. In the presence of an abnormal AT and concommitant PAD, the use of RA for peripheral or coronary catheterization and angioplasty is not recommended.

Keywords: Allen's test • Ishaemia • Transradial access

(c) Versita Sp. z 0.0

\section{Introduction}

Transradial (TR) approach for coronary and peripheral angiography and angioplasty has become a popular technique [1-5]. The Allen's test (AT), first described in 1929, could be used to determine the presence of collateral flow in the hand [6]. Due to high rate of false positive and negative results, modified Allen's test with pulsoximetry was introduced in the clinical practice.
Recently, angiographic background of modified AT was evaluated, but patients with peripherial arterial disease (PAD) were excluded in these studies [7]. Therefore, the present study was designed to assess reliability of AT in patients with symptomatic PAD. 


\section{Materials and methods}

\subsection{Study population}

The present study comprised 92 symptomatic patients with PAD (Rutherford class 2-6). Perfusion of the hand was assessed with AT and modified AT before outpatient peripheral angiography. At the end of each procedure, a transbrachial and subclavian angiography was also performed. Angiographic data of forearm arteries and palmar communications were analysed following each procedure by one expert in interventional radiology. Informed consent was obtained from each patient and the study protocol conformed to the ethical guidelines of the 1975 Declaration of Helsinki, as reflected in a priori approval by the institution's human research committee.

\subsection{Allen's test}

The AT was performed according to the following protocol. The examiner faced the patient, whose hand was supinated. Radial (RA) and ulnar (UA) arteries were then located by their pulses, and both arteries were compressed simultaneously by 4 fingers. During direct pressure, the patient was asked to clench and unclench his/her fist several times. The patient was then asked to relax his/her hand and extend fingers into a slightly flexed position while the examiner maintained pressure on the RA and UA. The hand at this point should appear blanched. Examiner then released the pressure on the UA and continued applying pressure on the RA. The return of color to the hand and fingers was noted. An abnormal AT result was defined as a recovery time of more than 5 seconds [8] (Figures 1 and 2).

Figure 1. Selective angiography shows patent forearm arteries, but the palmar arch is not complete (see arrows).

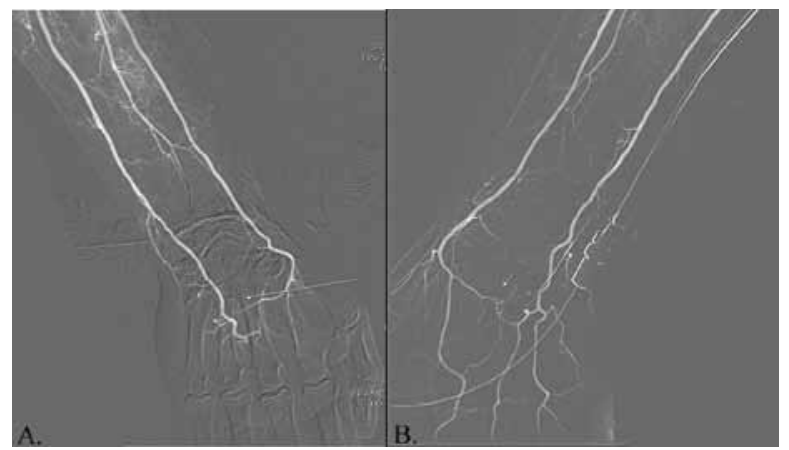

\subsection{Modified Allen's test}

Modified AT was performed with placing pulsoxymetry on the index finger. During dual RA and UA compressions, hand ischaemia was induced and oxygen saturation and waveform were assessed. Modified AT was considered positive if the oxygen saturation got lower than $70 \%$ on the index finger during compression and the waveform was diminished or weak.

\subsection{Angiography}

Angiography was performed according to the standard clinical practice. At the end of angiography the subclavian and brachial arteries were assessed by a pigtail catheter. The forearm vessels were visualised through a 4F sheath used for angiography. Two digital substraction angiography shots were performed, which showed hand circulation, as well. Routine measurements were done in the RA and UA at the wrist level. At the end of the angiography, subclavian and brachial arteries were assessed with a pigtail catheter. Vessels and lesions were analysed by using a computerized quantitative analysis system (General Electric, Fairfield, CT, US) after administration of intraarterial nitroglycerin (0.2 mg). Anatomic variations were investigated such as high origin of RA, RA and brachial artery loop, RA hypoplasia. If an atherosclerotic lesion was found in the RA or UA, quantitative measurements were taken at the site of the stenosis (lesion length, reference diameter, stenosis diameter and diameter stenosis). A stenosis was considered significant if quantitative measurement showed $>70 \%$ diameter narrowing.

Figure 2. Selective angiography shows an ulnar artery occlusion (Figure 2A) with patent palmar arch, and a critical ulnar artery stenosis with week and atherosclerotic palmar arch in Buerger disease (Figure 2B).

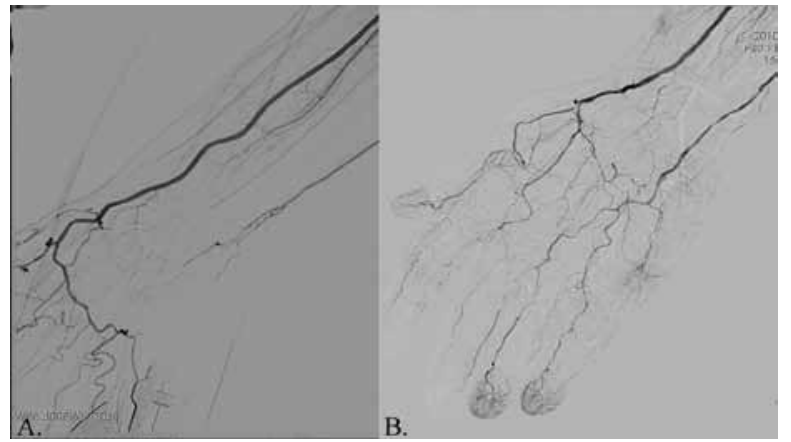




\subsection{Statistical analysis}

All statistical analysis was performed with a commercially available software Statistica 8.0 (StatSoft Inc., Tulsa, OK, USA). Continuous variables were expressed as mean \pm standard deviation, and were compared using unpaired $t$-tests. Dichotomous variables were compared by $\mathrm{X}^{2}$ and Fisher's exact-test. Probability values lower than 0.05 were considered to be significant.

\section{Results}

Results of Allen's tests. A strong pulsoxymetry signal at baseline could be detected in all subjects. All patients with positive AT showed positive modified AT (100\%). Oxygen saturation got lower than $70 \%$ in 42 patients $(87.5 \%)$ and the signal was diminished in 6 patients (12.5\%) representing a positive modified AT. During RA compressions, no symptoms were reported. Baseline demographic and clinical characteristics of patients with positive and negative AT are presented in Table 1.

Indications for peripheral angiography. The indication for peripheral angiography was critical limb ischaemia (Rutherford class 4-6) in 19 patients with positive AT $(39.6 \%)$ and in 13 patients with negative AT (29.5\%, p =0.31). Intermittent claudication (Rutherford class 2-3) indicated angiography in 29 patients with positive AT $(60.4 \%)$ and in 31 patients with negative AT $(70.5 \%, p=0.31)$. Indications for peripheral angiography are presented in Table 2.

Results of peripheral angiography are presented in Table 3.

Forearm arteries: Significant subclavian or brachial artery stenosis could not be detected in the presented population. The mean diameter of RA and UA was 2.28 $\pm 0.50 \mathrm{~mm}$ and $1.76 \pm 0.66 \mathrm{~mm}$ at the wrist level. Angiography showed significant $\mathrm{RA}$ stenosis in 6 cases $(6.5 \%)$ and UA stenoses in 32 cases (34.8\%). Significant RA stenosis $(n=6,12.5 \%)$ and UA stenosis $(n=26,54.2 \%)$ were found in 30 patients with positive AT $(62.5 \%)$. In patients with negative AT, only UA showed significant stenoses $(n=6,13.6 \%)$. The interosseal artery showed no significant stenosis in none of cases, but the artery reached the wrist level only in 42 patients (45.6\%).

Anatomic variations: Anatomic variations could be observed in 8 out of 92 patients (8.7\%). RA variations included 6 tortuous configurations $(6.5 \%)$, one hypoplasia

Table 1. Demographic and clinical charecteristics of patient with positive and negative Allen's test

\begin{tabular}{|c|c|c|c|}
\hline Number & $\begin{array}{l}\text { Positive AT } \\
(n=48)\end{array}$ & $\begin{array}{l}\text { Negative AT } \\
(\mathrm{n}=44)\end{array}$ & $p$ value \\
\hline Age (years) & $65.1 \pm 10.5$ & $64.2 \pm 9.3$ & 0.65 \\
\hline Male (\%) & $39(81)$ & $33(75)$ & 0.47 \\
\hline Current smoker (\%) & $20(42)$ & $18(41)$ & 0.94 \\
\hline Hypertension (\%) & $36(75)$ & $30(68)$ & 0.47 \\
\hline Diabetes mellitus (\%) & $12(25)$ & $16(36)$ & 0.24 \\
\hline Dyslipidemia (\%) & $8(17)$ & $3(7)$ & 0.06 \\
\hline Renal insufficiency (\%) & $0(0)$ & $1(2)$ & 0.29 \\
\hline Previous coronary or peripheral intervention (\%) & $6(13)$ & $10(23)$ & 0.20 \\
\hline Previous thrombosis (\%) & $4(8)$ & $1(2)$ & 0.20 \\
\hline Previous stroke (\%) & $11(23)$ & $5(11)$ & 0.14 \\
\hline Thrombophilia (\%) & $1(2)$ & $1(2)$ & 0.95 \\
\hline Malignancy (\%) & $5(10)$ & $3(7)$ & 0.54 \\
\hline Autoimmune disease (\%) & $1(2)$ & $1(2)$ & 0.95 \\
\hline
\end{tabular}

Abbreviations: $A T=$ Allen's test 
Table 2. Indications for peripheral angiography

\begin{tabular}{l|lcc}
\hline & $\begin{array}{l}\text { Positive AT } \\
(\mathrm{n}=48)\end{array}$ & $\begin{array}{l}\text { Negative AT } \\
(\mathrm{n}=44)\end{array}$ & p value \\
\hline \hline Intermittent claudication (\%) & $29(60.4)$ & $31(70.4)$ & 0.31 \\
Critical limb ischaemia (\%) & $19(39.6)$ & $13(29.5)$ & 0.31 \\
$\begin{array}{l}\text { Intermittent claudication } \\
+ \text { significant forearm stenosis (\%) }\end{array}$ & $23(47.9)$ & $7(15.9)$ & 0.05 \\
$\begin{array}{l}\text { Critical limb ischaemia } \\
+ \text { significant forearm stenosis (\%) }\end{array}$ & $15(31.3)$ & $8(18.2)$ & \\
\hline
\end{tabular}

Abbreviations: AT = Allen's test

Table 3. Results of peripheral angiography

\begin{tabular}{|c|c|c|c|c|}
\hline & & $\begin{array}{l}\text { Positive AT } \\
(n=48)\end{array}$ & $\begin{array}{l}\text { Negative AT } \\
(n=44)\end{array}$ & $p$ value \\
\hline \multirow[t]{8}{*}{ Upper extremity } & Significant subclavian and anonym artery stenosis (\%) & $0(0)$ & $0(0)$ & 1.00 \\
\hline & Significant brachial artery stenosis (\%) & $0(0)$ & $0(0)$ & 1.00 \\
\hline & Significant radial artery stenosis (\%) & $6(12.5)$ & $0(0)$ & 0.03 \\
\hline & Significant ulnar artery stenosis (\%) & $26(54.2)$ & $6(13.6)$ & $<0.0001$ \\
\hline & Palmar arch - incomplete (\%) & $17(35.4)$ & $11(25.0)$ & 0.37 \\
\hline & - weak (\%) & $12(25.0)$ & $14(31.8)$ & 0.50 \\
\hline & - strong (\%) & 19 (39.6) & $19(43.2)$ & 0.83 \\
\hline & Anatomic abnormality (sum) (\%) & 38 (79.2) & $15(34.1)$ & $<0.0001$ \\
\hline \multirow{4}{*}{$\begin{array}{l}\text { Lower } \\
\text { extremity }\end{array}$} & lliac artery stenosis (\%) & 19 (39.6) & $13(29.5)$ & 0.38 \\
\hline & Femoral artery stenosis (\%) & $32(66.7)$ & $37(84.1)$ & 0.06 \\
\hline & Popliteal artery stenosis (\%) & $15(31.3)$ & $4(9.1)$ & 0.01 \\
\hline & Below-the-knee lesion (\%) & $29(60.4)$ & 19 (43.2) & 0.14 \\
\hline
\end{tabular}

Abbreviations: $A T=$ Allen's test

Brought to you by | University of Szeged 
(1.1\%), and one radioulnar loop (1.1\%). High origin of the RA was not found in the investigated population. UA showed no anatomic variations in this population.

Palmar arch: Incomplete communications were found between the superficial and deep palmar arches in 17 patients with positive AT (35.4\%) and in 11 patients with negative AT $(25.0 \%, p=0.37)$. Normal palmar arch was found in 31 patients with positive AT (64.6\%) and in 33 patients with negative AT $(75.0 \%, p=0.37)$.

Anatomic abnormalities: Thirty-eight patients with positive AT had anatomic abnormality in the forearm arteries or in the palmar arch $(79.2 \%)$. Anatomic abnormality in the forearm arteries or in the palmar arch could be detected in 15 cases with negative AT (34.1\%, $p<0.0001$ ) (Table 3).

Prognostic value of AT. Positive prognostic value of AT for anatomic abnormality was found to be $79.2 \%$, while negative predictive value of AT was $65.9 \%$. Sensitivity and specificity proved to be $71.7 \%$ and $74.4 \%$, respectively.

\section{Discussion}

The dominant site of access during angiography has been the femoral artery for over two decades and continues to be today. Alternative access sites, including radial, brachial and axillary arteries, have been employed in clinical scenarios, where groin access is contraindicated or the bleeding risk is to high. At first, brachial and axillary access were introduced, but these approaches have been associated with a relatively high risk of vascular and nerve complications [9,10]. Furthermore, cannulation of these arteries involves a potential thrombotic occlusion, which may put the entire distal artery at risk. The TR route achieves an excellent procedural success rate and virtually eliminates access site complications, allows rapid ambulation and even procedures to be performed in an outpatient setting. Randomised trials show benefit for the TR access in clinical situations associated with a higher risk of bleeding complications, such as the management of acute myocardial infarction [2,3], obese patients [11] and in cases of concomittant PAD [12]. Despite the safety of TR route, the zero vascular complication hypothesis is not true. The complication profile of TR access is different from those related to the femoral route with no life-threatening complications and no need of vascular surgery and blood transfusions. Reported complications include brachial artery dissection and perforation [13,14], arteriovenous fistula formation [15] and pseudoaneurysm formation [16]. The most frequent complication after TR access is RA occlusion, which occurs in $3-5 \%$ of the cases [17]. Predictive factors for
RA occlusion include long duration of catheterisation, high sheath/artery ratio, heparin dosage, longer sheath and prolonged compression times [17]. There are case reports of digital ischemia in patients undergoing RA cannulation in the surgical intensive care, perioperative setting, and after TR angioplasty [18]. The anatomic background of the very rare digital ishaemia following RA occlusion is due to double hand supply of the forearm, collaterals from the interosseus artery and double palmar arterial supply. The parallel arterial systems (RA and UA and paired proper digital arteries) allow the upper extremity to maintain normal perfusion at rest even in the setting of significant obstructive disease. The redundancy in the forearm and hand arterial systems is completed by multiple tributaries, which serve as collaterals in the setting of obstructive disease. In cases of RA/UA occlusion, collaterals from the mid-arm to the distal and/or proximal forearm and/or retrograde filling via the palmar arch may be observed.

Several methods have been introduced to assess patency of forearm arteries including AT [6], modified AT [7], pletysmography [7], Doppler ultrasound, segmental pressure measurement etc. AT is an easy-to-perform method where there is no need for a device, but the test is limited by false positive and negative results. Jarvis et al. published $79.6 \%$ diagnostic accuracy at $5 \mathrm{~s}$ cut-off point and sensitivity and specificity were found to be $75.8 \%$ and $81.7 \%$, respectively [8]. There are some reports on digital ischemia requiring amputation in patients with a negative AT [18,19]. Greenwood et al. have investigated the effect of RA occlusion in patients previously screened by AT [20]. In this study RA was occluded for 30 minutes and patients were screened for hand ishaemia, UA flow and venous lactate level. Patients with positive AT had higher UA flow following RA occlusion than patients with negative AT $(240 \%$ vs $135 \%$ ), but flow velocity in the principal artery of the thumb was diminished better $(3.2 \mathrm{~cm} / \mathrm{s}$ vs $15.9 \mathrm{~cm} / \mathrm{s})$ and lactate level was increased higher in the thumb than in patients with negative AT.

These findings represent normal conditions, where UA is free of disease. The aim of the present work was designed to study a population with symptomatic PAD. Significant forearm stenosis was found in 38 patients $(41,3 \%)$ and palmar circulation was incomplete in 28 patients $(30.4 \%)$. Forearm anatomic problem could be encountered more frequently in patients with abnormal AT as compared to those with negative AT. Moreover, significant forearm stenosis was found more frequently in patients with positive AT than in cases with negative AT. However, the occurence of forearm stenosis was not significantly higher in patients with critical limb ischemia than in subjects with intermittent claudication. 
Conclusions. Although collateral circulation of the hand is dynamic in normal anatomical setting, forearm stenosis is highly frequent in the presence of PAD, which increases the possibility of hand ischaemia following RA occlusion. Regarding to the result of the present study, in the presence of an abnormal AT and concommitant PAD, the use of RA for peripheral or coronary catheterization

\section{References}

[1] Kiemeneij F, Laarman GJ, de Melker E. Transradial artery coronary angioplasty. Am Heart J 1995;129:1-7

[2] Cantor WJ, Puley G, Natarajan MK, et al. Radial versus femoral access for emergent percutaneous coronary intervention with adjunct glycoprotein llb/ IIIa inhibition in acute myocardial infarction--the RADIAL-AMI pilot randomized trial. Am Heart J 2005; 150:543-549

[3] Ruzsa Z, Ungi I, Horváth T, et al. Five-year experience with transradial coronary angioplasty in ST-segment-elevation myocardial infarction. Cardiovasc Revasc Med 2009;10:73-79

[4] Pinter L, Cagiannos C, Ruzsa Z, et al. Report on initial experience with transradial access for carotid artery stenting. J Vasc Surg. 2007;45:1136-1141

[5] Galli M, Tarantino F, Mameli S, et al. Transradial approach for renal percutaneous transluminal angioplasty and stenting: a feasibility pilot study. J Invasive Cardiol. 2002;14:386-390

[6] Allen A. Thromboangiitis obliterans: methods of diagnosis of chronic occlusive arterial lesions distal to the wrist with illustrative cases. Am J Med Sci 1929;178:237- 244

[7] Barbeau GR, Arsenault F, Dugas L, et al. Evaluation of the ulnopalmar arterial arches with pulse oximetry and plethysmography: comparison with the Allen's test in 1010 patients. Am Heart J 2004; 147:489-493

[8] Jarvis MA, Jarvis CL, Jones PR, et al. Reliability of Allen's test in selection on patients for radial artery harvest. Ann Thorac Surg 2000;70:1362-1365

[9] Kiemeneij F, Alarman GJ, Odekerken D, et al. A randomized comparison of percutaneous transluminal coronary angioplasty by the radial, brachial and femoral approaches: the Access study. J Am Coll Cardiol 1997;29:1269-1275

[10] Alvarez-Tostado JA, Moise MA, Bena JF, et al. The brachial artery: a critical access for endovascular procedures. J Vasc Surg 2009;49:378-385 and angioplasty is not recommended. Positive AT could have a better predictive value in forecasting underlying pathological conditions in patients with known PAD than negative AT in predicting normal anatomy. However, further studies are warranted in larger patient population focusing on the prediction of further events in this special patient subset.

[11] Benamer H, Louvard Y, Sanmartin M, et al. A multicentre comparison of transradial and transfemoral approaches for coronary angiography and PTCA in obese patients: the TROP registry. Eurolntervention 2007;3:327-332

[12] Hildick-Smith DJ, Walsh JT, Lowe MD, et al. Coronary angiography in the presence of peripheral vascular disease: femoral or brachial/radial approach? Catheter Cardiovasc Interv 2000;49:32-37

[13] Campeau L. Percutaneous radial artery approach for coronary angiography. Cathet Cardiovasc Diagn 1989;16:3-7

[14] Spaulding C, Lefevre T, Funck F, et al. Left radial approach for coronary angiography: results of a prospective study. Cathet Cardiovasc Diagn 1996;39:365-370

[15] Wu CJ, Lo PH, Chang KC, et al. Transradial coronary angiography and angioplasty in Chinese patients. Cathet Cardiovasc Diagn 1997;40:159-63.

[16] Fagih B, Beaudry Y. Pseudoaneurysm: a late complication of the transradial approach after coronary angiography. J Invasive Cardiol 2000;12:216-217

[17] Stella PR, Odekerken D, Laarman GJ, et al. Incidence and outcome of radial artery occlusion following transradial coronary angioplasty. Cathet Cardiovasc Diagn 1997;40:156-158

[18] Ruzsa Z, Pintér L, Kolvenbach R. Anterograde recanalisation of the radial artery followed by transradial angioplasty. Cardiovasc Revasc Med, 2010;11:266.e1-4

[19] Lee MK, Lee IO, Kong MH, et al. Surgical treatment of digital ischemia occurred after radial artery catheterization. J Korean Med Sci 2001;16:375-377

[20] Greenwood MJ, Della-Siega AJ, Fretz EB, et al. Vascular communications of the hand in patients being considered for transradial coronary angiography: is the Allen's test accurate? J Am Coll Cardiol. 2005;46:2013-2017 